\title{
First report of Melodogyne fallax hosted by Trifolium repens (white clover): implications for pasture and crop rotations in New Zealand
}

\author{
T. C. $\operatorname{Rohan}^{1}$ - L. T. Aalders ${ }^{1}$ • N. L. Bell ${ }^{1}$ F. A. Shah ${ }^{2}$
}

Received: 22 September 2015 / Accepted: 15 April 2016/Published online: 18 April 2016

(C) Australasian Plant Pathology Society Inc. 2016

\begin{abstract}
The root-knot nematode Meloidogyne fallax is reported for the first time from white clover roots in New Zealand. Identity of the nematodes from single egg mass culture was confirmed by DNA sequencing along with morphological characters of the juveniles and relative gall size. The implications of this and previous host records on the ability of farmers and growers to devise effective rotations to manage this nematode are discussed.
\end{abstract}

Keywords False Columbia Root-knot nematode $\cdot$ Fodder beet $\cdot$ Invasion potential $\cdot$ Host range

Meloidogyne fallax was first recorded in New Zealand in 1998 from potato (Solanum tuberosa) tubers, and infected cotula (Lepinella spp.) roots from lawn-bowling greens (Marshall et al. 2001). In July 2011 a sample of fodder beet (Beta vulgaris) was received at the AgResearch Nematology lab, Ruakura. The sample was from a crop which had been reported to have poor yield of uncertain cause. Many fine roots of the beet tubers were affected by root-knot nematode galls (Fig. 1). DNA extraction (Shah et al. 2009) and ITS sequencing (Shah et al. 2010) of single juvenile (ie J2) nematodes from some of these galls confirmed morphological observations that they were M. fallax. Further putative M. fallax eggs and J2s were extracted from beet crop fine roots and

N. L. Bell

nigel.bell@agresearch.co.nz

1 AgResearch, Ruakura Research Centre, Private Bag 3123, Hamilton, New Zealand

2 New Zealand Institute for Plant and Food Research Limited, Private Bag 4704, Christchurch 8140, New Zealand inoculated onto tomato plants (cv. Rutgers) to establish a culture of these nematodes. This culture was maintained in the Ruakura nematology glasshouse and subsequent DNA sequencing again confirmed these as M. fallax.

The first indication that white clover may host M. fallax was in April 2012 when a soil sample was taken below a patch of white clover in an unused stock access way at Ruakura. Upon extraction from the soil, nematodes morphologically and molecularly matching $M$. fallax were observed. In an attempt to confirm this, nematodes from the putative M. fallax tomato culture were inoculated into two pots of white clover seedlings in June 2012. One month post inoculation, all the white clover roots contained small galls with adult female egg masses.

To confirm the identity of the putative M. fallax from tomato culture, and its ability to be hosted by white clover, twelve white clover seedlings were each grown in a $10 \mathrm{ml}$ Eppendorf pipette-tip filled with 1:4 sand: potting mix. Two weeks after sowing, plants were inoculated with single egg masses of the putative $M$. fallax. Inoculated plants were maintained in a controlled environment room for 8 weeks at $20^{\circ} \mathrm{C}$, transferred to a $10 \mathrm{~cm}$ diameter pot filled with potting mix and maintained in the controlled environment room for a further 2 weeks. Subsequently, the pots were transferred to a glasshouse and maintained for 2 weeks, after which the roots were evaluated for galling. All inoculated plants produced galled roots. Egg masses with females were picked from root galls, cleaned thoroughly with distilled water and allowed to hatch in water at ambient temperature. Morphology of the second stage juveniles was observed through a microscope and single J2s picked for DNA extraction and subsequent ITS sequencing. Both morphological observations (particularly the short, broadly rounded tail terminus of $\mathrm{J} 2 \mathrm{~s}$, and small galls) (Hunt and Handoo 2009) and ITS sequences (99.8\% match with $M$. fallax NCBI Genbank accession from the Netherlands 


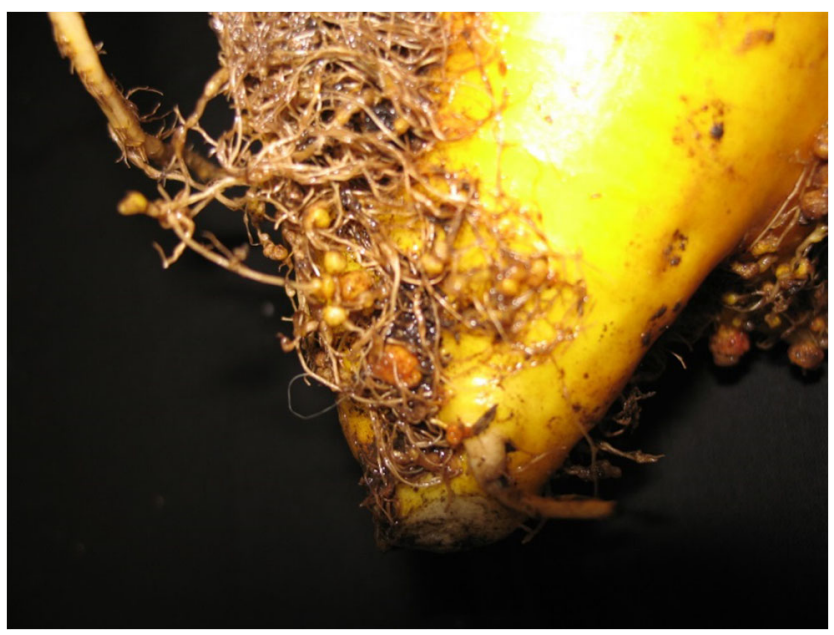

Fig. 1 Fodder beet fine roots galled by M. fallax

(AY281853)) confirmed the J2s arising from single egg masses on white clover were M. fallax. Female, male and juvenile specimens of these $M$. fallax are deposited in the National Nematode Collection of New Zealand (Accession number NNCNZ3201).

The BLASTN comparison of the fodder beet and white clover M. fallax sequences from our study to other New Zealand M. fallax sequences present in Genbank were a 99.6 and $100 \%$ match respectively, to accession numbers GU433344.1 (Nightshade) and JX465594.1 (Potato). The resulting sequences from fodder beet and white clover were deposited in the GenBank data base under accession numbers KP825332 (Beet1) and KP825333 (WC1) respectively. Both the white clover and fodder beet confirmations are first host records for this nematode from New Zealand. Interestingly, the first record of M. fallax in Australia was from a potato crop that was grown in a field previously in pasture dominated by white clover (Nobbs et al. 2001).

Subsequent to observing M. fallax galling on inoculated white clover roots, an experiment was carried out to determine the number of eggs required for invasion into white clover roots. This was part of a larger study to determine the invasion potential of a range of Meloidogyne spp. (Rohan et al. 2013). Rates of 5, 10, 50 or 100 eggs of the M. fallax from tomato culture were inoculated onto 10 replicates each of single 1-week-old white clover seedlings sown into the soil from which M. fallax had been observed in April 2012. Soil had been defaunated prior to sowing by two freeze/ thaw cycles. White clover plants were grown for a further 2 weeks before roots were removed from soil and stained (Rohan et al. 2006) to allow visualisation of nematodes inside roots (Fig. 2). Results of microscopic study of the roots showed that at a rate of 5 eggs/plant the M. fallax could invade roots and develop into females, suggesting that a very low inoculum is required to establish a new population of this nematode. M. fallax reproduces by facultative meiotic parthenogenesis (van der Beek and Karssen 1997) so a single female developing within inoculated roots can give rise to a new population.

M. fallax has been found widely within both the North and South Island of New Zealand from both cropping and pasture fields (Marshall et al. 2001; Shah et al. 2010) and the incidence of occurrence in fields appears to be increasing (pers obs). Additionally, M. fallax parasitizes a wide range of monocotyledonous and dicotyledonous plants. Crops and cropping weed hosts include potato (Solanum tuberosa), carrot (Daucus carota), tomato (Lycopersicon esculentum), wheat (Triticum aestivum), barley (Hordeum vulgare), sugar beet (Beta vulgaris cultivars 'Accord' and 'Univers'), black salsify (Scorzonera hispanica), hairy nightshade (Solanum physalifolium) and black nightshade (S. nigrum) (Den Nijs et al. 2004; Shah et al. 2010). Pasture hosts include perennial and Italian ryegrass (Lolium perenne and L. multiflorum respectively), lucerne (Medicago sativa) and chicory (Chicorium intybus) (Den Nijs et al. 2004). With the addition of white clover and fodder beet to this host list, growers and farmers in New Zealand need to avoid including two or more of these hosts in a rotation to minimise the risk of building up damaging populations.
Fig. 2 Stained white clover root infected with $M$. fallax. Infective $\mathrm{J} 2$ stage invading root tip (left) and galls on roots with adventitious roots arising from them (right)
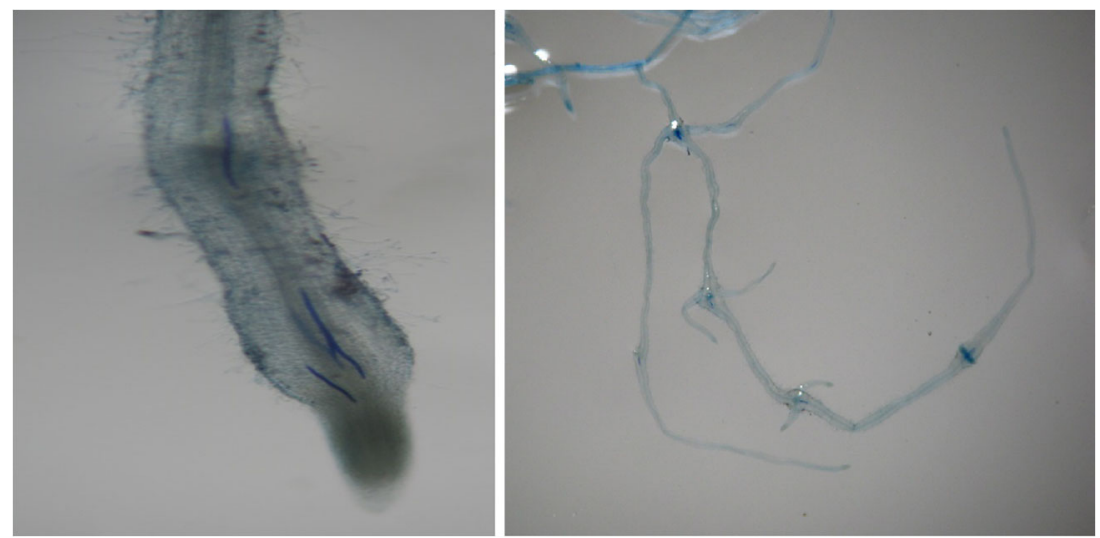
An earlier assessment (Bell et al. 2006) of rotations that could be used to reduce root-knot nematode populations in pasture (considered to be M. trifoliophila and/or M. hapla in that assessment) suggested that inclusion of successive crops of turnips (Brassica rapa var rapa), Italian ryegrass and turnips before re-establishing pasture would be successful. Whether this would still be the case with M. fallax is unclear as the host suitability of turnips to this nematode appears to be unknown. The closely-related $M$. chitwoodi can reproduce on turnips (Fourie et al. 1998) so that it is difficult to predict if this rotation strategy would be suitable for M. fallax control. Clearly, host suitability testing of turnips to M. fallax is required. Maize (Zea mays) is, at the most, a poor host for $M$. fallax (Davis and Venette 2004), so would be a useful part of any pasture rotation where management of this nematode was important.

Crop rotation of potato with pasture is often carried out in New Zealand (Cheah et al. 2008), in part to overcome the effects of the potato cyst nematodes Globodera pallida and G. rostochiensis (Marshall 1993). This practice may need to be reviewed, taking into account the ability of $M$. fallax to build up in potatoes and in both the white clover and ryegrass components of pasture. It may be that a check for the presence of M. fallax should be made prior to contemplating planting a potato crop from pasture. It is possible this nematode will pose an increasing yield restriction in productive environments as it becomes more prevalent.

\section{References}

Bell NL, Hardwick S, Eerens JPJ, James TK (2006) Managing biological succession in intensive pastoral ecosystems for improved production and sustainability. NZ Plant Protect 59:271-280
Cheah LH, Marsh AT, Hedderley D, Falloon RE (2008) Crop rotation with brassicas reduces Phytophthora populations in potato soil. NZ Plant Protect 61:256-260

Davis EE, Venette RC (2004) Mini risk assessment. False Columbia rootknot nematode: Meloidogyne fallax Karssen (Nematoda: Heterogeridae). USDA Cooperative Agricultural Pest Survey Pest Risk Assessment. http://www.aphis.usda.gov/plant health/ plant pest info/pest detection/downloads/pra/mfallaxpra.pdf

Den Nijs LJMF, Brinkman H, van der Sommen ATC (2004) A Dutch contribution to knowledge on phytosanitary risk and host status of various crops for Meloidogyne chitwoodi Golden et al. 1980 and M. fallax Karssen, 1996: an overview. Nematology 6:303-312

Fourie H, Zijlstra C, McDonald AH (1998) ITS-PCR sequence-based identification of Meloidogyne chitwoodi from Mooi River, South Africa, and screening of crops for host suitability. Afr Plant Protect 4:107-111

Hunt DJ, Handoo ZA (2009) Taxonomy, identification and principal species. In: Perry RN, Moens M, Starr JL (eds) Root-knot nematodes. CABI International, Wallingford, pp 55-97

Marshall JW (1993) Detecting the presence and distribution of Globodera rostochiensis and G. pallida mixed populations in New Zealand using DNA probes. N Z J Crop Hortic Sci 21:219-223

Marshall JW, Zijlstra C, Knight K (2001) First record of Meloidogyne fallax in New Zealand. Australas Plant Pathol 30:283-284

Nobbs JM et al (2001) First record of Meloidogyne fallax in Australia. Australas Plant Pathol 30:373

Rohan TC, Bell NL, Lee NDF, Aalders LT (2006) Efficacy of root digestion and maceration in determining abundance of rootinhabiting nematodes. NZ Plant Protect 59:166-171

Rohan TC, Aalders LT, Bell NL (2013) Determining the propagule size required for Meloidogyne species to establish in managed and native soil in New Zealand. NZ Plant Protect 66:377 (abstract)

Shah F, Bell NL, Bulman SR (2009) Morphological and molecular confirmation of Xiphinema brevicollum, a nematode from the virusvectoring $X$. americanum group, from New Zealand. Australas Plant Pathol 38:500-504

Shah FA, Falloon RE, Bulman SR (2010) Nightshade weeds (Solanum spp.) confirmed as hosts of the potato pathogens Meloidogyne fallax and Spongospora subterranea f. sp. subterranea. Australas Plant Pathol 39:492-498. doi:10.1071/ap10059

van der Beek G, Karssen G (1997) Interspecific hybridization of meiotic parthenogenetic Meloidogyne chitwoodi and M. fallax. Phytopathology 87:1061-1066 